\title{
Coping strategies and mood profiles in patients with multiple sclerosis
}

\author{
Estratégias de enfrentamento e perfis de humor em pacientes com esclerose múltipla

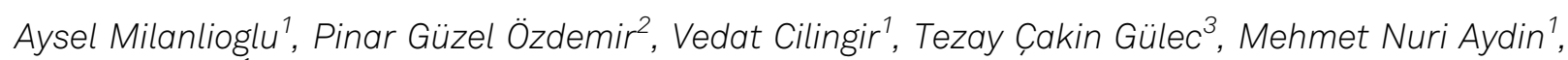 \\ Temel Tombul'
}

\begin{abstract}
Objective: The aim of the present study was to investigate the coping strategies, mood characteristics and the association between these aspects in patients diagnosed with multiple sclerosis and healthy subjects. Method: Fifty consecutive patients who were diagnosed with multiple sclerosis according to McDonald criteria and thirty-one healthy subjects were included in the study. In addition to the sociodemographic form, Expanded Disability Status Scale (EDSS), Coping Orientation for Problem Experiences Scale (COPE), and Profile of Mood States (POMS) tests were applied to the participants. Results: Non-functional coping strategies were significantly higher in the secondary-progressive type $(p \leq 0.05)$. Depression-dejection, fatigue-inertia and total POMS scores were significantly higher in the secondary-progressive type ( $p \leq 0.05)$. Conclusion: The results of our study demonstrate the importance of rehabilitation programs that encourage exercise among patients with multiple sclerosis to increase vigor-activity levels.
\end{abstract}

Keywords: multiple sclerosis, depression, disability, mood, coping strategy.

RESUMO

Objetivo: Investigar as estratégias de enfrentamento, as características de humor e a associação entre estes aspectos em pacientes com diagnóstico de esclerose múltipla em comparação a indivíduos saudáveis. Método: Foram incluídos no estudo 50 pacientes com diagnóstico de esclerose múltipla de acordo com os critérios de McDonald e 31 pessoas saudáveis. Além da caracterização sócioeconômica, foram aplicados a todos os pacientes testes para avaliar o Expanded Disability Status Scale (EDSS), o Coping Orientation for Problem Experiences Scale (COPE) e o Profile of Mood States (POMS). Resultados: Escores referentes a estratégias de enfrentamento não funcionais foram significativamente maiores na forma secundariamente progressiva ( $p \leq 0.05)$. Escores relativos a depressão-abatimento, fadiga-inércia e escores totais POMS foram significativamente maiores na forma secundariamente progressiva ( $\leq \leq 0.05$ ). Conclusão: Os resultados deste estudo mostram a importância de programas de reabilitação que encorajem os pacientes com esclerose múltipla a praticar exercícios com maiores niveis de vigor e atividade.

Palavras-chave: esclerose múltipla, depressão, incapacidade, humor, estratégias de enfrentamento.

Multiple sclerosis (MS) is known as a chronic, autoimmune, inflammatory and demyelinating disease ${ }^{1}$. The incidence of MS tends to increase at 20-40 years of age and it is more common (3:1) in women compared to men $^{2}$. Depending on the central nervous system regions involved, patients may experience various symptoms mainly motor, somato-sensorial, visual, cognitive and psychiatric disturbances ${ }^{3,4}$. Moreover, this disease may accompany some psychiatric conditions related to mood, behavior and personality disorders, or may be seen with depression, hypomania and anxiety due to the course of the disease or the side effects of treatment ${ }^{1,4}$.
Coping strategies play an important role in orientation to challenge conditions. "Coping" is defined as resisting against the events or factors that cause stress for the individuals and the cognitive, emotional and behavioral reactions of the individuals in an attempt to endure these circumstances. Thus, coping strategies and the degree of stressor experiences are closely associated. For example, effective coping strategies protect the individuals from cognitive, environmental and biological factors that cause anxiety. They are unique for each individual and may vary depending on various factors such as age, gender, cultural aspects and disease characteristics ${ }^{5}$.

${ }^{1}$ Neurology Division, Yuzuncu YIl University, Van, Turkey;

${ }^{2}$ Psychiatry Division, Yuzuncu Yıl University, Van, Turkey;

${ }^{3}$ Neurology Division, Erzurum Training and Research Hospital, Neurology, Erzurum, Turkey.

Correspondence: Aysel Milanlioglu; Yuzuncu YIl University, Faculty of Medicine, Neurology; Van 65100, Turkey; E-mail: ayselmilanlioglu@yahoo.com

Conflict of interest: There is no conflict of interest to declare.

Received 07 January 2014; Received in final form 30 April 2014; Accepted 20 May 2014. 
It is also important to be aware of coping strategies in addition to receiving medical treatment in order to have better life experiences for MS disease. Because, in patients with MS, similar to other chronic diseases, the failure in psychological, physical and social functions lead the individual to develop certain coping strategies in order to minimize or fully cope with the adverse outcomes of the disorder within the context of his/her culture and system of values ${ }^{6,7}$. However, mood characteristics play particularly important role among the factors that may affect coping strategies in patients with MS. Moreover, depression can negatively affect these skills ${ }^{8}$.

In patients with MS, in addition to the disorder itself, the occupational stress related to working within society, economical and social stress and the additional stressful events may adversely affect the course and nature of the disease. Therefore, coping strategies in MS can be defined as resistance not only against the disease itself but also against the events or factors that cause stress for the individuals.

Additionally, mood characteristics are one of the important factors that influence the compliance and response to treatment in chronic conditions. For this reason, mood alterations have a significant effect on the course of the disease. Because MS is a chronic disorder requiring long-term treatment and also, it is highly important to be aware of the mood characteristics that affect the course of the disease and treatment ${ }^{4}$.

There are a limited number of studies investigating the coping strategies and mood characteristics in patients with MS $^{9,10,11}$. For instance, Mohr and colleagues ${ }^{12}$ found higher rates of depression and lower levels of orientation and emotional coping skills among the patients. On the other hand, Lynch and colleagues ${ }^{13}$ found no correlation between disability status and psychological variables, and demonstrated that MS patients predominantly exhibited emotional coping strategies.

In the present study, we aimed to investigate the coping strategies, mood characteristics and the association between these aspects in patients diagnosed with MS and healthy subjects.

\section{METHOD}

Fifty consecutive patients who were diagnosed with MS according to McDonald criteria and thirty-one healthy subjects were included in the current study. The inclusion criteria were as follows: volunteering to participate, literacy, $>18$ and $<65$ years of age, being in non-relapsing phase, no corticosteroid therapy during the preceding 1 month, no previous psychiatric or physical disorder, no abuse of alcohol or other substances. Informed consent was obtained for each patient who met the inclusion criteria and the following forms and scales were applied for these individuals:

- EDSS (Expanded Disability Status Scale): It is used to determine the extent of neurological disability in patients with MS. The scale was filled by a neurologist informed about the physical examination and medical history of the patient. The severity of disability is rated according to the EDSS score. Patients with an EDSS score of 3.5 or less are considered as mildly disabled whereas those with a score of 4 or more are considered as severely disabled. The EDSS range among our patients was calculated as $1-8^{14,15}$.

- COPE (Coping Orientation for Problem Experiences Scale): It is a self-reporting scale consisting of 60 questions and 15 subscales. Each subscale contains four questions and provides information on separate coping skills. In conclusion, the scores obtained in different subscales allow interpretation about which coping strategy is predominantly used by the individuals. The subscales are as follows: problem-based methods include planning, use of instrumental social support, active coping, restraint, suppression of competing activities while emotion-based methods include use of emotional social support, positive reinterpretation and growth, religious coping, humor and acceptance. Non-functional coping strategies are focus on and venting of emotions, denial, behavioral disengagement, mental disengagement, and substance use ${ }^{16}$. To give an example, instrumental social support can be described as practical, informational or tangible support rather than just words of advice. Additionally, positive reinterpretation and growth are processes of choosing positive emotions from stimuli in the environment and applying them to perceptions and beliefs and also create an outlook that translates into a new or better chosen reality.

- Profile of Mood States (POMS): It was developed to define and assess situational and short-term mood alterations with a rapid and reliable method ${ }^{17}$. The questions of the scale are randomly arranged and certain questions are combined under 6 different mood states. The mood states are: "tension-anxiety”, "vigor-activity”, "depressiondejection", "fatigue-inertia", "anger-hostility", and "confusion-bewilderment". Subscale scores consist of the scores obtained from the questions of each subscale, and total POMS score is calculated by subtracting the "vigor-activity" score from the total scores of the other five subscales. High scores in five subscales and a high total score indicate greater mood disturbances.

- Statistical assessment: Data were assessed with SPSS windows 16.0. Frequency was used for the overall distribution of variables, and variance analysis was used for the comparison of categorical variables. Duncan test was applied to determine different groups. The results were expressed as mean and standard deviation. Pearson's correlation analysis was used to assess the association 
between intra-group data. The statistical significance level was accepted as $\mathrm{p} \leq 0.05$.

\section{RESULTS}

Thirty-six $(72 \%)$ of the patients with MS were females, and fourteen $(28 \%)$ were males while nineteen $(61.3 \%)$ of the control group were females, and twelve (38.7\%) were males. There was no significant difference between the participants regarding age, gender or sociocultural characteristics. Disease duration was 6.4 years in the MS group with a mean EDSS of $2.9 \pm 2.2$. Relapsing-remitting type MS was present in fourty patients while ten patients had secondary-progressive type.

\section{Comparison of coping strategies among patients with MS and healthy individuals}

Patients with secondary-progressive type MS had significantly lower scores in positive reinterpretation and growth, suppression of competing activities, and planning compared to patients with relapsing-remitting type and the control group ( $\mathrm{p} \leq 0.05)$. However, they had significantly higher scores in behavioral disengagement $(p=0.001)$. Acceptance was significantly higher in patients with MS compared to the control $(p=0.003)$. There was no significant difference in other subscales. Findings were presented in Table 1.

\section{Comparison of mood characteristics among patients with MS and healthy individuals}

The scores of depression-dejection and fatigue-inertia subscales and total POMS scores were significantly higher in patients with relapsing-remitting and secondary-progressive type MS compared to the control group ( $\mathrm{p} \leq 0.05)$. These results were shown in Table 2 .

\section{Comparison of mood characteristics and coping strategies by gender in patients with MS and the control group}

Depression-dejection, fatigue-inertia, and total POMS scores were higher in women with MS compared to the control group (p:0.03, p:0.01, p:0.03, respectively). Behavioral disengagement and acceptance were also higher in women with MS (p:0.03, p:0.009, respectively). While there was no difference regarding mood characteristics among men, they had significantly higher scores in denial among coping methods (p:0.04). They were explained in detail in Table 3.

\section{The correlation between coping strategies, mood characteristics, and EDSS scores in patients with MS}

The correlation between coping strategies, mood characteristics, and EDSS scores in patients with MS revealed a positive correlation between overall EDSS scores and fatigue-inertia, confusion-bewilderment, vigor-activity, and behavioral disengagement while there was a negative correlation with vigor-activity, positive reinterpretation and growth, and planning. In terms of difference between genders, there was a positive correlation between EDSS scores and confusion-bewilderment, humor, and behavioral disengagement in men. In women, EDSS scores showed a positive correlation with fatigue-inertia, total POMS, and behavioral disengagement and a negative correlation with confusion-bewilderment, positive reinterpretation and growth, and mental disengagement.

\section{The correlation between mood characteristics and coping strategies in patients with MS}

There was a negative correlation between depression and suppression of competing activities while there was a positive correlation between depression and substance use. As for anxiety, there was a positive correlation with substance use and non-functional coping strategies. There was a significant negative correlation between confusionbewilderment and active coping, suppression of competing activities, and problem-based coping methods. As for fatigue, there was a positive correlation with behavioral disengagement, substance use, and humor; and also a negative correlation with suppression of competing activities.

Depression and behavioral disengagement were positively correlated in women while there was a negative correlation between depression and active coping in women. Fatigue was negatively correlated with planning, use of instrumental social support, suppression of competing activities, and problem-based methods, and positively correlated with behavioral disengagement. Vigor-activity was positively correlated with problem-based methods such as active coping, planning, suppression on competing activities, and negatively correlated with behavioral disengagement.

\section{DISCUSSION}

The results of our investigation revealed significant differences regarding mood characteristics particularly in patients with secondary-progressive MS compared to those with relapsing-remitting MS and control group. In terms of mood profile; depression-dejection, fatigue-inertia and total POMS scores were significantly higher in secondary-progressive group ( $\mathrm{p} \leq 0.05)$. Multiple sclerosis itself decreases quality of life by interfering with social life and daily activities and by disturbing emotional well-being of the patients ${ }^{18,19}$. Depression, anxiety and mood disorders have been reported as important factors that affect disease progression. Supporting our findings, there are some reports showing higher rates of depression and anxiety together with more 
Table 1. Comparison of coping strategies among relapsing-remitting, secondary-progressive type of multiple sclerosis and control group.

\begin{tabular}{|c|c|c|c|c|}
\hline \multirow[t]{2}{*}{ COPE } & $\begin{array}{l}\text { Relapsing-remitting } \\
\qquad(n=40)\end{array}$ & $\begin{array}{l}\text { Secondary-progressive } \\
\qquad(n=10)\end{array}$ & $\begin{array}{l}\text { Control } \\
(n=31)\end{array}$ & \multirow[t]{2}{*}{$\mathrm{p}$} \\
\hline & Mean $\pm S D$ & Mean $\pm S D$ & Mean $\pm S D$ & \\
\hline Positive reinterpretation and growth & $12.75 \pm 2.36 \mathrm{~A}$ & $9.9 \pm 3.7 \mathrm{~B}$ & $12.9 \pm 2.02 \mathrm{~A}$ & $0.003 *$ \\
\hline Mental disengagement & $10.2 \pm 2.3$ & $9.0 \pm 3.3$ & $10.2 \pm 2.7$ & 0.407 \\
\hline Focus on and venting of emotions & $11.4 \pm 2.9$ & $11.9 \pm 2.4$ & $11.5 \pm 2.4$ & 0.879 \\
\hline Use of instrumental social support & $11.4 \pm 3.07$ & $10.7 \pm 2.4$ & $11.4 \pm 2.5$ & 0.727 \\
\hline Active coping & $12.02 \pm 2.4$ & $10.7 \pm 2.5$ & $12.09 \pm 2.49$ & 0.275 \\
\hline Denial & $7.8 \pm 2.9$ & $8.7 \pm 2.5$ & $7.0 \pm 13.05$ & 0.32 \\
\hline Religious coping & $14.15 \pm 2.5$ & $13.9 \pm 3.9$ & $13.16 \pm 2.28$ & 0.303 \\
\hline Humor & $8.2 \pm 3.01$ & $8.9 \pm 2.4$ & $7.6 \pm 3.3$ & 0.49 \\
\hline Behavioral disengagement & $7.8 \pm 2.8 \mathrm{~A}$ & $10.1 \pm 2.07 \mathrm{~B}$ & $6.2 \pm 2.3 \mathrm{~A}$ & $0.001 *$ \\
\hline Restraint & $10.2 \pm 2.6$ & $11.0 \pm 1.6$ & $9.5 \pm 2.24$ & 0.197 \\
\hline Use of emotional social support & $10.9 \pm 2.69$ & $11.4 \pm 2.6$ & $10.5 \pm 2.65$ & 0.66 \\
\hline Substance use & $5.4 \pm 2.7$ & $6.4 \pm 2.3$ & $4.7 \pm 1.3$ & 0.12 \\
\hline Acceptance & $11.3 \pm 2.8 \mathrm{~A}$ & $11.1 \pm 2.02 \mathrm{~A}$ & $9.3 \pm 1.7 \mathrm{~B}$ & $0.003^{*}$ \\
\hline Suppression of competing activities & $11.02 \pm 2.4 \mathrm{~A}$ & $9.1 \pm 2.8 \mathrm{~B}$ & $11.0 \pm 2.06 \mathrm{~A}$ & $0.05^{\star}$ \\
\hline Planning & $11.7 \pm 2.4 \mathrm{~A}$ & $10.0 \pm 2.9 \mathrm{~B}$ & $12.2 \pm 2.8 \mathrm{~A}$ & $0.05^{\star}$ \\
\hline
\end{tabular}

Different letters indicate significantly differences between the groups; COPE: coping orientation for problem experiences scale; SD: standard deviation; ${ }^{*} \mathrm{p} \leq 0.05$.

profound loss of emotional control in patients with secondary-progressive $\mathrm{MS}^{10}$. Our study also demonstrated higher total POMS scores in women compared to men, indicating more profound effects on mood state and mood characteristics such as depression-dejection, and fatigue-inertia. Therefore, it can be concluded that mood state is further disturbed in female patients with MS. In this respect, female gender may be an unfavorable factor regarding disease progression.

In terms of coping strategies, our results showed significantly higher rates of non-functional coping strategies in the secondary-progressive MS $(\mathrm{p} \leq 0.05)$. Among these strategies; behavioral disengagement and acceptance were significantly higher in patients with MS compared to the control. Behavioral disengagement and acceptance are important mainstays of the behavioral hypothesis to explain why depression occurs in some individuals. Indeed, depression is one of the most common psychiatric conditions seen in patients with $\mathrm{MS}^{20}$. Furthermore, depression is more common in secondary-progressive type compared to relapsing-remitting MS and the etiology may be related to these non-functional coping strategies commonly seen in patients with MS. However, no correlation was found between depression and disease duration or functional disturbance ${ }^{21,22}$. Similarly, we found no correlation between disease duration and depression or other mood characteristics and coping strategies.

There are limited number of studies investigating the coping strategies and mood characteristics which affect quality of life, therapeutic goals and treatment compliance in patients with MS. According to McCabe and colleagues?, coping strategies are important factors that affect quality of life in patients with MS. They are usually classified in two groups: methods based on problem solving, and emotion-based methods. Methods based on problem solving include coping methods related to the main reason of the problem, and emotional coping methods include coping methods related to the emotional effect resulting from the main reason. While the methods based on problem solving

Table 2. Comparison of mood characteristics among relapsing-remitting, secondary-progressive type of multiple sclerosis and control group.

\begin{tabular}{|c|c|c|c|c|}
\hline \multirow[t]{2}{*}{ POMS } & $\begin{array}{l}\text { Relapsing-remitting } \\
\qquad(n=40)\end{array}$ & $\begin{array}{l}\text { Secondary-progressive } \\
\qquad(n=10)\end{array}$ & $\begin{array}{l}\text { Control } \\
(n=31)\end{array}$ & $p$ \\
\hline & Mean $\pm S D$ & Mean $\pm S D$ & Mean $\pm S D$ & \\
\hline Depression-dejection & $25.5 \pm 12.7 \mathrm{AB}$ & $29.2 \pm 9.3 \mathrm{~A}$ & $19.7 \pm 8.8 B$ & $0.028^{*}$ \\
\hline Anger-hostility & $17.8 \pm 11.1$ & $17.7 \pm 9.7$ & $14.2 \pm 7.3$ & 0.28 \\
\hline Fatigue-inertia & $13.12 \pm 6.5 \mathrm{AB}$ & $14.8 \pm 5.8 \mathrm{~A}$ & $9.8 \pm 4.6 \mathrm{~B}$ & $0.02 *$ \\
\hline Confusion-bewilderment & $10.9 \pm 5.5$ & $12.7 \pm 3.5$ & $9.03 \pm 4.5$ & 0.08 \\
\hline Vigor-activity & $18.0 \pm 5.95$ & $14.7 \pm 6.2$ & $19.6 \pm 6.2$ & 0.08 \\
\hline Tension-anxiety & $16.02 \pm 6.3$ & $16.8 \pm 6.2$ & $13.6 \pm 4.9$ & 0.17 \\
\hline Total POMS & $65.1 \pm 39.1 \mathrm{AB}$ & $76.5 \pm 34.5 \mathrm{~A}$ & $46.9 \pm 27.7 \mathrm{~B}$ & $0.027 *$ \\
\hline
\end{tabular}

Different letters indicate significantly differences between the groups; POMS: profile of mood states; SD: standard deviation; ${ }^{*} \mathrm{p} \leq 0.05$. 
Table 3. Comparison of mood characteristics and coping strategies according to gender in patient with multiple sclerosis (MS) and control group.

\begin{tabular}{|c|c|c|c|c|c|c|}
\hline & \multicolumn{3}{|c|}{ Males } & \multicolumn{3}{|c|}{ Females } \\
\hline & $\begin{array}{c}\text { MS } \\
\text { Mean } \pm S D\end{array}$ & $\begin{array}{l}\text { Control } \\
\text { Mean } \pm S D\end{array}$ & $p$ & $\begin{array}{c}\text { MS } \\
\text { Mean } \pm S D\end{array}$ & $\begin{array}{l}\text { Control } \\
\text { Mean } \pm S D\end{array}$ & $p$ \\
\hline \multicolumn{7}{|l|}{ POMS } \\
\hline Depression-dejection & $20.7 \pm 10.8$ & $17.083 \pm 9.07$ & 0.360 & $28.38 \pm 12.07$ & $21.4 \pm 8.5$ & $0.03^{*}$ \\
\hline Anger-hostility & $13.3 \pm 10.5$ & $12.41 \pm 7.9$ & 0.80 & $19.5 \pm 10.4$ & $15.4 \pm 6.8$ & 0.12 \\
\hline Fatigue-inertia & $10.1 \pm 4.8$ & $8.5 \pm 4.2$ & 0.37 & $14.7 \pm 6.4$ & $10.6 \pm 4.8$ & $0.01^{*}$ \\
\hline Confusion-bewilderment & $8.5 \pm 4.8$ & $6.5 \pm 2.9$ & 0.209 & $12.3 \pm 5.0$ & $10.6 \pm 4.7$ & 0.21 \\
\hline Vigor-activity & $17.0 \pm 6.3$ & $19.5 \pm 5.2$ & 0.28 & $17.4 \pm 6.09$ & $19.6 \pm 6.8$ & 0.22 \\
\hline Tension-anxiety & $14.0 \pm 6.05$ & $11.7 \pm 5.04$ & 0.318 & $17.02 \pm 6.2$ & $14.8 \pm 4.6$ & 0.19 \\
\hline Total POMS & $49.4 \pm 33.7$ & $36.7 \pm 27.6$ & 0.31 & $74.4 \pm 37.9$ & $53.4 \pm 26.5$ & $0.03^{\star}$ \\
\hline \multicolumn{7}{|l|}{ COPE } \\
\hline Active coping & $12.2 \pm 2.1$ & $12.08 \pm 2.6$ & 0.89 & $11.5 \pm 2.6$ & $12.10 \pm 2.4$ & 0.48 \\
\hline Planning & $12.7 \pm 2.7$ & $10.5 \pm 2.9$ & 0.06 & $11.7 \pm 2.4$ & $12.0 \pm 2.9$ & 0.71 \\
\hline Restraint & $9.9 \pm 2.9$ & $8.8 \pm 1.8$ & 0.27 & $10.5 \pm 2.26$ & $9.9 \pm 2.39$ & 0.37 \\
\hline Use of instrumental social support & $11.3 \pm 2.2$ & $11.6 \pm 2.3$ & 0.73 & $11.3 \pm 3.21$ & $11.26 \pm 2.6$ & 0.96 \\
\hline Suppression of competing activities & $11.5 \pm 2.1$ & $10.2 \pm 2.5$ & 0.17 & $10.8 \pm 2.6$ & $10.68 \pm 2.0$ & 0.86 \\
\hline Positive reinterpretation and growth & $11.7 \pm 2.9$ & $12.7 \pm 1.8$ & 0.30 & $12.3 \pm 2.8$ & $13.0 \pm 2.1$ & 0.40 \\
\hline Religious coping & $14.2 \pm 3.17$ & $13.0 \pm 2.3$ & 0.25 & $14.02 \pm 2.7$ & $13.2 \pm 2.3$ & 0.31 \\
\hline Humor & $6.5 \pm 1.5$ & $7.0 \pm 1.7$ & 0.15 & $8.3 \pm 3.0$ & $8.05 \pm 4.06$ & 0.75 \\
\hline Acceptance & $10.57 \pm 2.4$ & $8.9 \pm 1.4$ & 0.053 & $11.5 \pm 2.7$ & $9.6 \pm 1.8$ & $0.009 *$ \\
\hline Use of emotional social support & $10.8 \pm 2.3$ & $10.5 \pm 2.7$ & 0.78 & $11.0 \pm 2.8$ & $10.5 \pm 2.69$ & 0.504 \\
\hline Focus on and venting of emotions & $10.2 \pm 3.09$ & $11.4 \pm 1.6$ & 0.27 & $12.0 \pm 2.5$ & $11.6 \pm 2.86$ & 0.680 \\
\hline Denial & $9.07 \pm 3.4$ & $6.5 \pm 2.2$ & $0.04^{\star}$ & $7.6 \pm 2.5$ & $7.5 \pm 3.4$ & 0.892 \\
\hline Behavioral disengagement & $8.4 \pm 3.3$ & $6.5 \pm 1.5$ & 0.07 & $8.2 \pm 2.7$ & $6.1 \pm 2.7$ & $0.01 *$ \\
\hline Mental disengagement & $10.3 \pm 2.5$ & $9.5 \pm 2.9$ & 0.43 & $9.8 \pm 2.6$ & $10.6 \pm 2.7$ & 0.243 \\
\hline Substance use & $6.3 \pm 3.9$ & $4.3 \pm 1.15$ & 0.09 & $5.3 \pm 2.08$ & $5.0 \pm 1.4$ & 0.569 \\
\hline
\end{tabular}

COPE: coping orientation for problem experiences scale; POMS: profile of mood states; SD: standard deviation; ${ }^{*}$ p $\leq 0.05$.

reduce mental disturbance, emotion-based approaches may increase such disturbances. Approaches based on problem solving therefore provide better orientation when patients encounter stressful circumstances. However, this complex correlation is affected by individual differences as well as disease characteristics. Problem-based coping methods are less common and orientation is poor in patients with MS compared to the overall population. Long-term studies in patients with MS have shown that problem-based coping methods are more reliable whereas emotion-based coping methods are less reliable to provide better orientation regarding the disease. Among these coping strategies, use of instrumental social support and positive reinterpretation have been found to be predictors of improved quality of life ${ }^{23}$.

The present study has been conducted in a relatively narrow age group sharing a common general culture without any other known diseases apart from MS. In terms of gender related difference, seeking social support and coping methods based on problem solving appear to be less common in men compared to women'. Regarding coping strategies, denial appears to be more common in men whereas acceptance and behavioral disengagement are more common in women. Different individual characteristics (such as neuroticism) have been reported to affect non-functional coping methods in patients with MS compared to healthy subjects ${ }^{24,25}$. Disease progression affects quality of life as well as coping strategies. As expected, the condition is worse for patients with secondary-progressive MS compared to relapsing-remitting type. Montel and Bungener ${ }^{10}$ have also shown the tendency to emotion-based coping strategies in patients with secondary-progressive type.

There is evidence demonstrating that depression has a greater effect on coping strategies compared to the degree of disability; on the other hand, it is in favor of emotionbased coping methods ${ }^{8,13,26}$. Depressive emotional state has shown a positive correlation with behavioral disengagement whereas there was a negative correlation with active coping, planning and problem-based coping methods. According to the findings of the present study, vigor-activity scores were positive correlated with positive reinterpretation and growth, active coping, planning, and emotional and problem-based coping methods. Therefore, our results demonstrated that the exercise and training programs aiming to increase vigor-activity scores in patients with MS are important not only for disease prognosis but also for the coping strategies. McCabe and $\mathrm{McKern}^{27}$ reported that training and intervention programs related to health status, coping strategies and mood characteristics are also important for patients with MS. They stated that these programs are effective and important regarding quality of life and psychological well-being in male and female patients with MS. However, whether mood characteristics affect coping 
methods or coping methods affect mood still remains a controversial subject.

One of the most important limitations of our study was the limited number of patients. It did not demonstrate causation but only provided an assessment. Further studies with large sample size are required to evaluate whether treatment changes coping strategies.

As a conclusion, providing rehabilitation for mood states and utilizing programs to increase the level of physical activity in patients with MS are important. Furthermore, training programs should be conducted to improve coping methods based on problem solving. Our result indicated that vigor-activity levels are valuable in terms of coping strategies not only regarding physical effects but also regarding cognitive and mental aspects in patients with MS. However, as mentioned before studies with large samples are required to determine the correlation between disease progression and quality of life in MS.

\section{References}

1. National Multiple Sclerosis Society. Multiple Sclerosis Information Sourcebook. New York, NY: Information Resource Center and Library of the National Multiple Sclerosis Society; 2005.

2. Akpınar Z, Gündüz ZB. Multiple sclerosis and cognitive impairment. Selçuk Tıp Derg 2011;28:75-79.

3. Fazzito MM, Jordy SS, Tilbery CP. Psychiatric disorders in multiple sclerosis patients. Arq Neuropsiquiatr 2009;67:664-667.

4. Burks JS, Bigley GK, Hill HH. Rehabilitation challenges in multiple sclerosis. Ann Indian Acad Neurol 2009;12:296-306.

5. Ağargün MY, Beșiroğlu L, Kıran ÜK, Özer OA, Kara H. COPE (Bașa Çıkma Tutumlarını Değerlendirme Ölçeği): Psikometrik özelliklere ilișkin bir ön çalıșma. Anadolu Psikiyatri Dergisi 2005;6:221-226.

6. Folkman S, Lazarus RS, Gruen RJ, DeLongis A. Appraisal, coping, health status, and psychological symptoms. J Pers Soc Psycho 1986;50:571-579

7. Ostell A. Coping, problem solving and stress: a framework for intervention strategies. Br J Med Psychol 1991;64:11-24.

8. Arnett PA, Higginson Cl, Voss WD, Randolph JJ, Grandey AA. Relationship between coping, cognitive dysfunction and depression in multiple sclerosis. Clin Neuropsychol 2002;16:341-355.

9. McCabe MP, McKern S, McDonald E. Coping and psychological adjustment among people with multiple sclerosis. J Psychosom Res 2004;56:355-361

10. Montel SR, Bungener C. Coping and quality of life in one hundred and thirty five subjects with multiple sclerosis. Mult Scler 2007;13:393-401.

11. Lode K, Bru E, Klevan G, Myhr KM, Nyland H, Larsen JP. Coping with multiple sclerosis: a 5-year follow-up study. Acta Neurol Scand 2010;122:336-342.

12. Mohr DC, Goodkin DE, Gatto N, Van Der Wende J. Depression, coping and level of neurological impairment in multiple sclerosis. Mult Scler 1997;3:254-258.

13. Lynch SG, Kroencke DC, Denney DR. The relationship between disability and depression in multiple sclerosis: the role of uncertainty, coping, and hope. Mult Scler. 2001;7:411-416.

14. Kurtzke JF. Rating neurological impairment in multiple sclerosis and Expanded Disability Status Scale (EDSS). Neurology 1983; 33:1444-1452.
15. Goldman MD, Marrie RA, Cohen JA. Evaluation of the six-minute walk in multiple sclerosis subjects and healthy controls. Mult Scler. 2008;14:383-390.

16. Carver CS, Scheier MF, Weintraub JK. Assessing coping strategies: a theoretically based approach. J Pers Soc Psychol 1989;56:267-283.

17. McNair DM, Lorr M, Droppleman LF. Manual for the profile of mood states. First ed., San Diego: Educational and Industrial Testing Service, 1971

18. D’alisa S, Miscio G, Baudo S, Simone A, Tesio L, Mauroi A Depression is the main determinant of quality of life in multiple sclerosis: A classification-regression (CART) study. Disab Rehab 2006;28:307-314

19. Koçer E, Koçer A, Yaman M, Eryılmaz M, Özdem S, Börü ÜT. Multip skleroz olgularında yașam kalitesi: Fiziksel özürlülük ve depresyonun etkisi? J Mood Disord 2011;1:63-67.

20. Emre U, Ergün U, Yıldız H, Coskun Ö, İnan LE. Multipl sklerozda depresyon. Düșünen Adam 2003;16:53-57.

21. Galeazzi GM, Ferrari S, Giaroli G, et al. Psychiatric disorders and depression in multiple sclerosis outpatients: impact of disability and interferon beta therapy. Neurol Sci 2005;26:255-262.

22. Iwasaki $\mathrm{Y}$, Iwamoto $\mathrm{K}$, Igarashi $\mathrm{O}$, et al. Depression in multiple sclerosis. Acta Neurol Scand 2005;111:209

23. Pakenham KI. Adjustment to multiple sclerosis: application of a stress and coping model. Health Psychol 1999;18:383-392.

24. Ratsep T, Kallasmaa T, Pulver A, Gross-Paju K. Personality as a predictor of coping efforts in patients with multiple sclerosis. Mult Scler 2000;6:397-402.

25. Goretti B, Portaccio E, Zipoli V, et al. Coping strategies, psychological variables and their relationship with quality of life in multiple sclerosis. Neurol Sci 2009;30:15-20.

26. Jean VM, Beatty WW, Paul RH, Mullins L. Coping with general and disease-related stressors by patients with multiple sclerosis: relationships to psychological distress. Mult Scler 1997;3:191-196.

27. McCabe MP, McKern S. Quality of life and multiple sclerosis: comparison between people with multiple sclerosis and people from the general population. J Clin Psychol Med Settings 2002;9:287-295. 